\title{
ARD
}

\section{Clinical and ultrasonographic predictors of joint replacement for knee osteoarthritis: results from a large, 3-year, prospective EULAR study}

P G Conaghan, M A D'Agostino, M Le Bars, et al.

Ann Rheum Dis 2010 69: 644-647 originally published online May 10, 2009 doi: 10.1136/ard.2008.099564

Updated information and services can be found at:

http://ard.bmj.com/content/69/4/644.full.html

These include:

References This article cites 15 articles, 9 of which can be accessed free at: http://ard.bmj.com/content/69/4/644.full.html\#ref-list-1

Email alerting Receive free email alerts when new articles cite this article. Sign up in the service box at the top right corner of the online article.

Notes

To order reprints of this article go to:

http://ard.bmj.com/cgi/reprintform

To subscribe to Annals of the Rheumatic Diseases go to:

http://ard.bmj.com/subscriptions 


\title{
Clinical and ultrasonographic predictors of joint replacement for knee osteoarthritis: results from a large, 3-year, prospective EULAR study
}

\author{
P G Conaghan, ${ }^{1}$ M A D'Agostino, ${ }^{2} \mathrm{M}$ Le Bars, ${ }^{3} \mathrm{G}$ Baron, ${ }^{4,5} \mathrm{~N}$ Schmidely, ${ }^{3} \mathrm{R}$ Wakefield, ${ }^{1}$ \\ P Ravaud ${ }^{5}$ W Grassi, ${ }^{6}$ E Martin-Mola, ${ }^{7}$ A So, ${ }^{8}$ M Backhaus, ${ }^{9}$ M Malaise, ${ }^{10}$ P Emery, ${ }^{1}$ \\ M Dougados ${ }^{11}$
}

${ }^{1}$ Section of Musculoskeletal Disease, University of Leeds and NIHR Leeds Musculoskeletal Biomedical Research Unit Leeds, UK

${ }^{2}$ Rheumatology Department, Ambroise Pare Hospital, UVSO University, Boulogne-Billancourt, France

${ }^{3}$ Bristol Myers-Squibb, France ${ }^{4}$ Epidemiology, Biostatistics and Clinical Research Department,

Bichat Hospital, France 5INSERM E0357 and University Paris 7, Paris, France ${ }^{6}$ Rheumatology Department, Jesi Hospital, Jesi, Italy ${ }^{7}$ Rheumatology Department, La Paz Hospital, Madrid, Spain ${ }^{8}$ Rheumatology Department, Vaudois Hospital, Lausanne. Switzerland

${ }^{9}$ Rheumatology Department, Charité University Hospital, Berlin, Germany

${ }^{10}$ Rheumatology Department, Saint Tiltman Hospital, Liege, Belgium

${ }^{11}$ Paris-Descartes University, Medicine Faculty, UPRES-EA 4058 \& APHP, Cochin Hospital, Rheumatology B Department, Paris, France

\section{Correspondence to}

Professor Maxime Dougados, Paris-Descartes University, Medicine Faculty, UPRES-EA 4058 \& APHP, Rheumatology B Department, Cochin Hospital, 27, rue du Faubourg St Jacques, 75014 Paris, France; maxime. dougados@cch.ap-hop-paris.fr

Accepted 3 March 2009 Published Online First 10 May 2009

\section{ABSTRACT \\ Objectives To determine clinical and ultrasonographic predictors of joint replacement surgery across Europe in primary osteoarthritis $(0 \mathrm{~A})$ of the knee.}

Methods This was a 3-year prospective study of a painful OA knee cohort (from a EULAR-sponsored, multicentre study). All subjects had clinical evaluation, radiographs and ultrasonography (US) at study entry. The rate of knee replacement surgery over the 3-year follow-up period was determined using Kaplan-Meier survival data analyses. Predictive factors for joint replacement were identified by univariate log-rank test then multivariate analysis using a Cox proportional-hazards regression model. Potential baseline predictors included demographic, clinical, radiographic and US features.

Results Of the 600 original patients, 531 (88.5\%), mean age $67 \pm 10$ years, mean disease duration $6.1 \pm 6.9$ years, had follow-up data and were analysed. During follow-up (median 3 years; range 0-4 years), knee replacement was done or required for 94 patients (estimated event rate of $17.7 \%)$. In the multivariate analysis, predictors of joint replacement were as follows: Kellgren and Lawrence radiographic grade (grade $\geq 1 \|$ vs $<1 \|$, hazards ratio $(H R)=$ 4.08 (95\% Cl 2.34 to 7.12), $\mathrm{p}<0.0001$ ); ultrasonographic knee effusion ( $\geq 4 \mathrm{~mm}$ vs $<4 \mathrm{~mm})(\mathrm{HR}=2.63(95 \% \mathrm{Cl}$ 1.70 to 4.06), $p<0.0001)$; knee pain intensity on a $0-100$ $\mathrm{mm}$ visual analogue scale ( $\geq 60$ vs $<60)(H R=1.81(95 \%$ $\mathrm{Cl} 1.15$ to 2.83), $p=0.01$ ) and disease duration ( $\geq 5$ years vs $<5$ years) ( $\mathrm{HR}=1.63$ (95\% $\mathrm{Cl} 1.08$ to 2.47$), \mathrm{p}=0.02$ ). Clinically detected effusion and US synovitis were not associated with joint replacement in the univariate analysis. Conclusion Longitudinal evaluation of this $\mathrm{OA}$ cohort demonstrated significant progression to joint replacement. In addition to severity of radiographic damage and pain, US-detected effusion was a predictor of subsequent joint replacement.

\section{INTRODUCTION}

Osteoarthritis (OA) of the knee is a major problem for ageing Western populations. ${ }^{1}$ A major part of the economic burden is related to joint replacement surgery. ${ }^{2}$ It would be advantageous to have predictors of subsequent joint replacement in order to prioritise research in these patients, examine reversible risk factors and provide cohorts for evaluating putative disease-modifying treatments. ${ }^{3}$ The limited prospective studies on joint replacement for OA suggest that radiographic severity, pain and global disease assessments, and willingness to consider surgery are the strongest predictors of subsequent joint replacement surgery. ${ }^{4}$ Such research highlights the complexity of joint replacement as an outcome measure in clinical trials, as patient perceptions of the need for surgery and potential side effects affect willingness to undergo a procedure; socioeconomic features are important and these factors are reflected in regional and national variations in use of joint replacement. ${ }^{35}$

Previous work has demonstrated the prevalence of synovitis in OA, ${ }^{6}$ and studies of predictors of joint replacement have been unable to adequately evaluate the inflammatory component of $\mathrm{OA}$ as they did not employ modern imaging techniques such as ultrasonography (US), which are the most sensitive way of evaluating the presence of synovitis. The importance of such synovitis in disease progression or its relationship to subsequent need for joint replacement is not clear.

We have previously reported the results of a large, cross-sectional, multinational EULAR study that employed clinical examination and US in a cohort with painful OA of the knee. ${ }^{7}$ This study demonstrated that synovial inflammation (either synovial hypertrophy or effusion) was very common and much more frequently detected with US than by clinical examination (47\% vs $30 \%$ ). However, it was not possible to derive useful clinical decision rules by which to identify patients with synovial inflammation, ${ }^{8}$ suggesting that only an imaging technique such as US will be useful in identifying these patients.

The aim of this study was to prospectively follow-up this EULAR cohort of patients with painful $O A$ of the knee and determine the rate of joint replacement at 3 years and the factors predicting surgery; in particular, whether US findings of synovial inflammation would be predictive of subsequent surgery. Joint replacement was judged by the performance of partial or total joint arthroplasty and also by patients being listed for surgery, or being considered as deserving of such surgery but being medically unfit.

\section{PATIENTS AND METHODS \\ Patients}

The cohort followed up in this study was from a multicentre European study conducted under the umbrella of the EULAR Standing Committee for International Clinical Studies Including Therapeutics Trials (ESCISIT), enrolling subjects from seven European countries (Belgium, France, Germany, 
Italy, Spain, Switzerland and the UK) who were recruited by 50 rheumatologists. ${ }^{7}$ Appropriate ethics committee permission was obtained in each country and written informed consent was obtained from every patient before study participation. The main inclusion criteria were as follows: age $\geq 18$, primary knee $O A$ according to the American College of Rheumatology definition, ${ }^{9}$ with radiographic Kellgren and Lawrence (K\&L) grade 1-4,10 11 symptoms of at least 6 months' duration, functional capacity 1-3 according to the Steinbrocker functional score ${ }^{12}$ and pain intensity at study entry $\geq 30 \mathrm{~mm}$ on a $100 \mathrm{~mm}$ visual analogue scale that asked about pain in the previous $48 \mathrm{~h}$ related to physical activities. Exclusion criteria included any known cause for secondary $\mathrm{OA}$, inflammatory arthritis, recurrent pseudogout and surgery on the study joint within the previous 12 months.

\section{Methods}

At baseline, all patients were examined by a rheumatologist, then a radiologist or second rheumatologist performed US of the study knee according to prespecified US parameters (details in D'Agostino et al'). Data were recorded by the investigators on two separate case report forms that were forwarded to a central data entry and quality-control service. Subsequently, the patients were invited for annual review, where information was recorded on whether joint replacement (total or unicompartmental) had been performed, or whether the patient had been listed for such surgery, or whether such surgery would have been performed if the patient had been medically fit.

\section{Statistical analysis}

Descriptive statistics were calculated for follow-up characteristics of the overall cohort, as well as the percentage of patients having knee replacement performed/required. The survival analysis was performed on all subjects with at least one contact. In order to determine the rate of joint replacement over the 3-year follow-up for the overall population, a survival curve was established using the Kaplan-Meier estimator. For subjects who were not prescribed knee replacement, the following censoring rules were applied: subjects who did not require knee replacement after years 1, 2 and 3 were censored at the date of contact of year 3; subjects who did not require knee replacement at year 1 and for whom no data were available at year 2 (no contact or missing data concerning knee replacement) were censored at date of contact of year 1; and subjects who did not require knee replacement at year 2 and for whom no data were available at year 3 (no contact or missing data concerning knee replacement) were censored at date of contact of year 2 .

The relationship between prescription of knee replacement and baseline characteristics was evaluated and no missing data were replaced, so only complete observations were used in the analyses. Predictive factors for joint replacement at 3 years were identified by univariate analysis using a log-rank test and HR. All pertinent patients' baseline characteristics identified in the univariate analysis $(p<0.20)$ were integrated in a multivariate analysis (Cox proportional-hazards regression model) in which the dependent variable was the time to performance/requirement for knee replacement, and the independent variables were the significant patient characteristics.

\section{RESULTS}

Of 643 subjects enrolled in the study, 600 patients were analysed in the cross-sectional part of the study (16 were missing a case report from either clinical examination or ultrasound and 27 had major protocol deviations). Out of these, 565 patients entered the extension phase and had at least one follow-up visit: of these, 33 could not be contacted for the 3-year follow up and one patient was excluded because the studied knee at follow-up was different from baseline. Therefore at 3 years, 531 patients were analysed, including 94 patients $(18 \%)$ with a knee replacement done $(64(12 \%))$ or required $(30(6 \%))$. Six of the knee operations were unicompartmental replacements.

The baseline characteristics of those completing 3 years of follow-up are presented in table 1, with the annual requirement for surgery according to defined surgical end points presented in table 2. The 3 -year survival rate was $82.3 \%$ (standard error 0.017). The survival curve is presented in figure 1 .

The baseline characteristics included and the results for the univariate analysis are presented in table 3. Of note, the WOMAC physical function subscale, age, clinical joint effusion, body mass index, gender, night awakening due to knee pain and

Table 1 Baseline characteristics of the subjects completing the 3-year follow-up

\begin{tabular}{ll}
\hline Parameters & Results \\
\hline Number & 531 \\
Age (years) (mean \pm SD) & $67 \pm 10$ \\
Women (\% of cohort) & 72.5 \\
$\mathrm{BMI}\left(\mathrm{kg} / \mathrm{m}^{2}\right.$, mean $\left.\pm \mathrm{SD}\right)$ & $30 \pm 5$ \\
$\mathrm{BMl}<30 \mathrm{~kg} / \mathrm{m}^{2}$ (\%) & 55.6 \\
Disease duration (years) & $6 \pm 7$ \\
Pain on VAS (mm) & $63 \pm 18$ \\
K\&L score: & \\
$\quad$ Grade $\leq 2$ (\% patients) & 44.6 \\
$\quad$ Grade 3-4 (\% patients) & 55.4 \\
Joint effusion (moderate-severe) at clinical examination (\% patients) & 34.1 \\
US hydarthrodial effusion (\% patients with effusion depth $\geq 4$ mm) & 41.3 \\
US synovitis (\% patients with synovial thickness $\geq 4 \mathrm{~mm}$ and diffuse or & 16.6 \\
nodular appearance) & \\
\hline
\end{tabular}

BMI, body mass index; K\&L, Kellgren and Lawrence; US, ultrasonography; VAS, visual analogue scale.

Table 2 Numbers (percentage) of patients reaching knee replacement over 3 years

\begin{tabular}{llll}
\hline & \multicolumn{2}{l}{ Knee replacement } & \\
\cline { 2 - 4 } Time & $\begin{array}{l}\text { Knee replacement } \\
\text { performed }\end{array}$ & Indication for surgery & Total \\
\hline Year 0-year 1 & $44(8)$ & $20(4)$ & $64(12)$ \\
Year 0-year 2 & $53(10)$ & $26(5)$ & $79(15)$ \\
Year 0-year 3 & $64(12)^{*}$ & $30(6)$ & $94(18)$ \\
\hline
\end{tabular}

$\mathrm{n}=31$ analysed at year 3 .

${ }^{*}$ Six had a unicompartmental knee replacement.

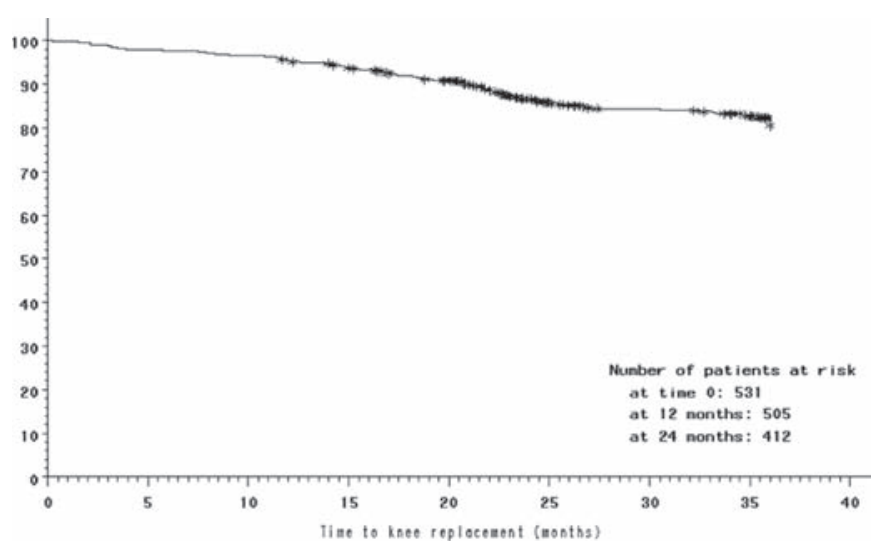

Figure 1 Survival curve for knee replacement. 
Table 3 Characteristics included and results of the univariate analysis

\begin{tabular}{llr}
\hline & HR (95\% Cl) & p Value \\
\hline Sex & $1.10(0.71$ to 1.72$)$ & 0.6582 \\
Age & $1.24(0.81$ to 1.89$)$ & 0.3144 \\
BMI & $1.15(0.76$ to 1.73$)$ & 0.5121 \\
Disease duration & $1.70(1.13$ to 2.55$)$ & 0.0109 \\
K\&L radiological grade & $4.67(2.73$ to 8.01$)$ & $<0.0001$ \\
Knee pain intensity on VAS & $1.82(1.17$ to 2.82$)$ & 0.0074 \\
Joint effusion at clinical examination & $1.15(0.75$ to 1.76$)$ & 0.5153 \\
Sudden aggravation of knee pain & $0.74(0.49$ to 1.13$)$ & 0.1617 \\
Duration of morning stiffness & $1.41(0.86$ to 2.32$)$ & 0.1686 \\
Night awakening due to knee pain & $1.07(0.69$ to 1.65$)$ & 0.7730 \\
WOMAC pain subscale & $1.45(0.94$ to 2.22$)$ & 0.0894 \\
WOMAC stiffness subscale & $1.36(0.88$ to 2.08$)$ & 0.1614 \\
WOMAC function subscale & $1.27(0.81$ to 2.00$)$ & 0.3053 \\
Patient's global assessment of clinical knee & $1.46(0.95$ to 2.25$)$ & 0.0832 \\
OA severity on VAS & $1.88(1.24$ to 2.84$)$ & 0.0031 \\
Physician's global assessment of clinical & & \\
knee OA severity on VAS & $3.06(2.00$ to 4.69$)$ & $<0.0001$ \\
Ultrasonographic knee effusion depth & $1.54(0.95$ to 2.50$)$ & 0.0826 \\
Ultrasonographic knee synovitis &
\end{tabular}

BMI, body mass index; HR, hazard ratio; K\&L, Kellgren and Lawrence; OA, osteoarthritis; VAS, visual analogue scale; WOMAC, Western Ontario and McMaster Universities Osteoarthritis Index.

US synovitis were not associated with joint replacement in the univariate analysis.

The following features were included in the multivariate analysis: K\&L radiological grade; US knee effusion; physician's global assessment of clinical knee OA severity; knee pain intensity; patient's global assessment of clinical knee OA; disease duration; US knee synovitis; WOMAC stiffness and pain subscales. The final predictors of joint replacement were K\&L radiographic grade ( $\mathrm{HR}=4.08$ (95\% CI 2.34 to 7.12$), \mathrm{p}<0.0001)$; ultrasonographic knee effusion ( $\mathrm{HR}=2.63$ (95\% CI 1.70 to 4.06 ), $\mathrm{p}<0.0001)$; knee pain intensity on a $0-100 \mathrm{~mm}$ visual analogue scale (HR=1.81 (95\% CI 1.15 to 2.83), $\mathrm{p}=0.01)$ and disease duration ( $\mathrm{HR}=1.63$ ( $95 \% \mathrm{CI} 1.08$ to 2.47 ), $\mathrm{p}=0.02$ ). Table 4 presents the baseline characteristics of these final predictors.

Table 4 Baseline characteristics of knee osteoarthritis predicting subsequent knee replacement

\begin{tabular}{|c|c|c|c|}
\hline & $\begin{array}{l}\text { No knee } \\
\text { replacement } \\
\text { (n=437) }\end{array}$ & $\begin{array}{l}\text { Knee } \\
\text { replacement } \\
(\mathrm{n}=94)\end{array}$ & $\begin{array}{l}\text { Total } \\
(n=531)\end{array}$ \\
\hline \multicolumn{4}{|c|}{ K\&L radiological grade } \\
\hline $\mathrm{n}$ & 437 & 94 & 531 \\
\hline Grade $0-2$ & $221(50.6)$ & $16(17.0)$ & $237(44.6)$ \\
\hline Grade 3-4 & $216(49.4)$ & $78(83.0)$ & $294(55.4)$ \\
\hline Missing data & 0 & 0 & 0 \\
\hline \multicolumn{4}{|c|}{ Ultrasonographic knee effusion depth } \\
\hline $\mathrm{n}$ & 436 & 94 & 530 \\
\hline$<4 \mathrm{~mm}$ & $279(64.0)$ & $32(34.0)$ & $311(58.7)$ \\
\hline$\geq 4 \mathrm{~mm}$ & $157(36.0)$ & $62(66.0)$ & $219(41.3)$ \\
\hline Missing data & 1 & 0 & 1 \\
\hline \multicolumn{4}{|c|}{ Knee pain intensity on VAS } \\
\hline $\mathrm{n}$ & 436 & 94 & 530 \\
\hline$<60 \mathrm{~mm}$ & $194(44.5)$ & $29(30.9)$ & $223(42.1)$ \\
\hline$\geq 60 \mathrm{~mm}$ & $242(55.5)$ & $65(69.1)$ & $307(57.9)$ \\
\hline Missing data & 1 & 0 & 1 \\
\hline \multicolumn{4}{|l|}{ Disease duration } \\
\hline $\mathrm{n}$ & 435 & 94 & 529 \\
\hline$<5$ Years & $259(59.5)$ & $42(44.7)$ & $301(56.9)$ \\
\hline$\geq 5$ Years & $176(40.5)$ & $52(55.3)$ & $228(43.1)$ \\
\hline Missing data & 2 & 0 & 2 \\
\hline
\end{tabular}

Results are shown as number or number (\%).

KGL, Kellgren and Lawrence; VAS, visual analogue scale.

\section{DISCUSSION}

This longitudinal study of painful knee OA has confirmed the importance of the extent of radiographic damage and patient symptoms in predicting subsequent need for joint replacement. In addition, it has demonstrated for the first time that an US feature of synovial inflammation, the US effusion, is also an independent predictor of joint replacement.

This study does not of course imply causation - that is, that synovial inflammation causes symptomatic/structural deterioration leading to joint replacement. The presence of joint inflammation may just reflect structural OA severity: it is plausible that synovial inflammation is associated with the degree of chondropathy, and increased levels of synovitis have been associated with more advanced cartilage loss. ${ }^{6}$ Synovial effusion and hypertrophy on MRI have also been associated with knee pain in OA. ${ }^{13} 14$

It is not surprising that US-detected effusion, but not clinically detected effusion, was a predictor of the outcome; we have previously demonstrated the increased sensitivity of US for this inflammatory feature. ${ }^{7}$ However, it may appear confusing that effusion but not synovial hypertrophy was associated with subsequent joint replacement need. Our previous work ${ }^{7}$ also demonstrated that larger effusions generally meant greater degree of synovial hypertrophy. However, because of the multiple ultrasonographer requirement for this multicentre study, we employed a conservative definition of synovial hypertrophy that may have made it difficult to demonstrate an association with synovial hypertrophy. A possible limitation of this work is that the ultrasound assessment included was only performed at a single time point; although anecdotal clinical reports suggest that inflammation varies over time in $\mathrm{OA}$, little has been reported on the longitudinal evaluation of synovitis using sensitive imaging modalities.

Using joint replacement as an outcome measure for $\mathrm{OA}$ is of course a complex issue that relates to national and local health priorities, individual surgeon choices, as well as patient willingness and comorbidities. ${ }^{3}{ }^{15}$ One limitation of this study is therefore the pragmatic outcome we have chosen. Additionally, we did not measure psychosocial factors such as anxiety and depression to assess their role in prediction. Certainly there is no international consensus on when joint replacement should be considered, and an ongoing OMERACT-OARSI initiative is developing a multidomain tool that will allow agreement on the level of OA severity that will act as a surrogate measure for the need for joint replacement. ${ }^{16}$

In summary, this large cohort of patients with painful knee OA has confirmed the importance of presenting features of pain and radiographic damage in predicting subsequent need for joint replacement. But it has also demonstrated that the presence of a large US-detected effusion may also be included in clinical models to predict surgical need.

Acknowledgements We gratefully acknowledge the contribution of all investigators. Italy: Dr Patrizia Blasetti, Dr Rossella De Angelis, Dr Antonella Farina, Dr Emilio Filippucci, Dr Gianni Lamanna. Spain: Dr Gema Bonilla, Dr Eugenio De Miguel. Germany: Dr Eugen Feist, Dr Sonja Kary, Dr Uwe Lang, Dr Anett Reißhauer, Dr Udo Schneider. Switzerland: Professeur Jean-Charles Gerster, Dr Laurent Malterre, Dr Nicholas Theumann, Dr Daniel Van Linthoudt, Dr Pascal Zufferey. Belgium: Dr Béatrice Andre, Dr Marie-Joëlle Kaiser, Dr Olivier Kaye, Dr Stefaan Marcelis.

Competing interests None.

Funding This study was supported in part by an unrestricted grant from Bristol Myers-Squibb.

Patient consent Obtained.

Ethics approval All involved multinational centres had local approval.

Provenance and peer review Not commissioned; externally peer reviewed. 


\section{REFERENCES}

1. Sharma L, Kapoor D, Issa S. Epidemiology of osteoarthritis: an update. Curr Opin Rheumatol 2006;18:147-56.

2. Parsons IM, IV, Sonnabend DH. What is the role of joint replacement surgery? Best Pract Res Clin Rheumatol 2004;18:557-72.

3. Maillefert JF, Hawker GA, Gossec L, et al. Concomitant therapy: an outcome variable for musculoskeletal disorders? Part 2: total joint replacement in osteoarthritis trials. J Rheumatol 2005;32:2449-51.

4. Gossec L, Tubach F, Baron G, et al. Predictive factors of total hip replacement due to primary osteoarthritis: a prospective 2 year study of 505 patients. Ann Rheum Dis 2005;64:1028-32.

5. Hawker GA, Guan J, Croxford R, et al. A prospective population-based study of the predictors of undergoing total joint arthroplasty. Arthritis Rheum 2006;54:3212-20.

6. Ayral X, Pickering EH, Woodworth TG, et al. Synovitis: a potential predictive factor of structural progression of medial tibiofemoral knee osteoarthritis - results of a 1 year longitudinal arthroscopic study in 422 patients. Osteoarthr Cartil 2005;13:361-7.

7. D'Agostino MA, Conaghan P, Le Bars M, et al. EULAR report on the use of ultrasonography in painful knee osteoarthritis. Part 1: prevalence of inflammation in osteoarthritis. Ann Rheum Dis 2005;64:1703-9.

8. Conaghan P, D'Agostino MA, Ravaud P, et al. EULAR report on the use of ultrasonography in painful knee osteoarthritis. Part 2: exploring decision rules for clinical utility. Ann Rheum Dis 2005;64:1710-14.
9. Altman R, Asch E, Bloch D, et al. Development of criteria for the classification and reporting of osteoarthritis. Classification of osteoarthritis of the knee. Diagnostic and Therapeutic Criteria Committee of the American Rheumatism Association. Arthritis Rheum 1986;29:1039-49.

10. Kellgren JH, Lawrence JS. Radiological assessment of osteo-arthrosis. Ann Rheum Dis 1957; 16:494-502.

11. Kellgren JH, Jeffrey MR, Ball J. Atlas of standard radiographs. In: The epidemiology of chronic rheumatism. Vol 2. Oxford: Blackwell Scientific, 1963.

12. Steinbrocker $\mathbf{0}$, Traeger $\mathrm{CH}$, Batterman $\mathrm{RC}$. Therapeutic criteria in rheumatoid arthritis. J Am Med Assoc 1949;140:659-62.

13. Hill CL, Gale DG, Chaisson CE, et al. Knee effusions, popliteal cysts, and synovial thickening: association with knee pain in osteoarthritis. J Rheumatol 2001;28:1330-7.

14. Hill CL, Hunter DJ, Niu J, et al. Synovitis detected on magnetic resonance imaging and its relation to pain and cartilage loss in knee osteoarthritis. Ann Rheum Dis 2007:66:1599-603.

15. Maillefert JF, Dougados M. Is time to joint replacement a valid outcome measure in clinical trials of drugs for osteoarthritis? Rheum Dis Clin North Am 2003;29:831-45.

16. Gossec L, Hawker G, Davis AM, et al. OMERACT/OARSI initiative to define states of severity and indication for joint replacement in hip and knee osteoarthritis. J Rheumatol 2007;34:1432-5. 